\title{
Daily Microaggressions and Related Distress among Black Women Living with HIV during the Onset of the COVID-19 Pandemic and Black Lives Matter Protests
}

\author{
Sannisha K. Dale ${ }^{1}$. Yue Pan $^{3}$. Nadine Gardner ${ }^{1}$. Sherence Saunders ${ }^{1} \cdot \operatorname{lan}$ A. Wright ${ }^{2} \cdot$ Cheri M. Nelson $^{3}$. \\ Jingxin Liu $^{3} \cdot$ Arnetta Phillips $^{1} \cdot$ Gail H. Ironson ${ }^{1}$ - Allan E. Rodriguez ${ }^{4} \cdot$ Maria L. Alcaide ${ }^{4}$. Steven A. Safren ${ }^{1}$. \\ Daniel J. Feaster ${ }^{3}$
}

Accepted: 22 May 2021 / Published online: 27 May 2021

(c) The Author(s), under exclusive licence to Springer Science+Business Media, LLC, part of Springer Nature 2021

\begin{abstract}
Black women living with HIV (BWLWH) in the U.S. face microaggressions based on race, gender, HIV-status, and sexual orientation. We examined changes in daily microaggressions and related distress among 143 BWLWH in Miami, FL. Microaggression-related distress increased from 52\% at baseline/October, peaked at 70\% during the holidays (November/ December), declined to 55\% in March when COVID-19 social distancing began, and peaked to 83\% in June/July 2020 during widespread Black Lives Matters protests. Baseline viral suppression was associated with lower microaggressions across the 9-months. Microaggression-related distress may change due to social context and research is needed on microaggressions and viral load overtime.
\end{abstract}

Keywords Black women living with HIV $\cdot$ Microaggression $\cdot$ COVID-19 $\cdot$ Black lives matter $\cdot$ Viral suppression

\section{Resumen}

Las mujeres de raza negra que viven con el VIH (MNVV) en los EE. UU. enfrentan microagresiones basadas en la raza, el género, el estado serológico del VIH y la orientación sexual. Examinamos los cambios en las microagresiones diarias y el estrés relacionado entre 143 MNVV en Miami, FL. El estrés relacionado con la microagresión aumentó del 52\% en la línea de base/octubre, alcanzó un máximo del 70\% durante las vacaciones (noviembre/diciembre), disminuyó al 55\% en marzo cuando comenzó el distanciamiento social por el COVID-19 y alcanzó un máximo del 83\% en junio/julio de 2020 durante las protestas generalizadas de Black Lives Matters. La supresión viral inicial se asoció con menores microagresiones durante los 9 meses. El estrés relacionada con la microagresión puede cambiar debido al contexto social y se necesitan investigaciones sobre las microagresiones y la carga viral con el tiempo.

Sannisha K. Dale

sdale@med.miami.edu

1 Department of Psychology, College of Arts and Sciences, University of Miami, 5665 Ponce de Leon Blvd, Miami, FL 33146, USA

2 Department of Economics, Miami Herbert Business School, University of Miami, Miami, FL, USA

3 Department of Public Health Sciences, University of Miami Miller School of Medicine, Miami, FL, USA

4 Division of Infectious Diseases, Department of Medicine, University of Miami Miller School of Medicine, Miami, FL, USA

\section{Introduction}

Black women represented over $60 \%$ of women living with HIV in the U.S. and Black women living with HIV (BWLWH) face unique adversities including microaggressions based on race, gender, HIV-status, and sexual orientation (for those who are sexual minorities) [1-3] that may negatively impact viral suppression via mental health struggles/distress and disruption of healthy behaviors (e.g. medication adherence) [1, 4]. Microaggressions are daily subtle insults, behaviors, and comments that are meant to devalue or demean marginalized groups [5-7]. Daily monitoring of microaggressions [8] and text-based ecological monetary assessments (EMA) $[9,10]$ have shown promising 
acceptability and feasibility in psychology, however it's not commonly used in the field of HIV [11]. Further, daily microaggressions among BWLWH and its relation to viral suppression remains understudied.

Being both Black and women, Black women experience gendered-racial microaggressions [12] which are insults at the intersection of both identities such as comments and jokes about their hair, body shape, facial features, voice level, temperament, etc. Examples of gendered racial microaggressions that Black women report include being accused of being angry when speaking in a calm manner, being told they are too assertive, and receiving negative comments when wearing their hair in its natural form [12]. As women living with HIV, Black women also experience microaggressions on the basis of their HIV status (such as having others suggest that they should not be having sex due to their HIV status) [13-15]. For BWLWH who are gay, bisexual, or queer they also face microaggressions based on their sexual orientation (e.g. being made to feel invisible or unwelcomed) $[2,6,16]$.

Researchers examining the experiences of microaggressions, racism, and sexism have recognized the benefit of utilizing daily ecological monetary assessments (EMA) measures to better assess their frequency and associations with outcomes. For instance, scholars have used a daily diary methodology among African Americans to capture microaggressions and daily experiences with racism and found the method to be reliable and valid [8]. Phone technology has validly captured daily assessments of sexism [17] and of daily stressors among people living with HIV [11]. In addition, EMA approaches in the field of psychology have begun to improve our understanding of other stressors, emotions, and behaviors, but is still not commonly used in the HIV field $[9,10]$. Such assessments are necessary to inform the development of EMA-based interventions (EMIs), which deliver psychological interventions via mobile devices while individuals are engaged in their daily lives [10] and show promise in existing literature.

There are no previously published studies examining microaggressions among BWLWH in relation to viral suppression. Studies primarily among Black and Latino MSM living with HIV have found that macro acts of discrimination (e.g. denied housing, denied employment, assault, distruction of property) based on race, HIV-status, and sexual orientation are negatively related to medication adherence, engagement in care, and viral suppression [18, 19]. Crosssectional work among BWLWH has found associations between gendered racial microaggressions and HIV-related barriers to care engagement $[4,20]$. While engagement in care and HIV medication adherence are necessary behaviors in order to achieve viral suppression, ultimately viral suppression is the end goal [21]. However, to date no study among BWLWH have investigated nor linked viral suppression with microaggressions.

To our knowledge, this is the first study designed to assess the everyday experiences of microaggressions among BWLWH using a text-based ecological monetary assessment (EMA). Notably, data collection began/occurred over a time that allows for a look at microaggressions (and related distress) in the midst of social contexts such as the onset of COVID-19 in the U.S. in March 2020 and Black Lives Matters protests. In a sample of BWLWH we examine and present preliminary findings on (a) how daily microaggressions and distress change overtime, (b) how microaggressions relate to baseline demographics (e.g. income), viral suppression, and alcohol and substance use, and (c) how daily microaggressions and related distress are associated with self-reported medication adherence at three time points. Based on existing literature noted above we hypothesized that daily microaggressions would be inversely related to medication adherence and viral suppression, however our analyses of how daily microaggressions and related distress may change within social context (i.e. COVID-19, protests) was exploratory in nature. Findings may echo the importance of monitoring microaggressions among BWLWH.

\section{Methods}

\section{Participants and Recruitment}

Between October 2019 and January 2020, BWLWH in the Southeastern U.S. were recruited for a longitudinal study: Project MMAGIC (Monitoring Microaggressions and Adversities to Generate Interventions for Change). Recruitment efforts consisted of calling BWLWH from a list of BWLWH who previously gave consent to be contacted by the research program as well as distributing flyers and posters at community clinics and health centers, hospitals, community events, and community-based organizations. Once participants expressed interest, a phone screen was conducted to determine if they met the criteria to be scheduled for an in-person baseline visit. To be scheduled for a baseline visit, participants had to meet seven inclusion criteria: (1) Living with HIV, (2) Identify as Black and/or African American, (3) Age 18 or older, (4) Cis-gender woman, (5) English speaking, (6) Capable of completing and fully understanding the informed consent process and procedures, and (7) Own a cell phone with text and internet capacity. 
At the baseline visit participants gave written informed consent, completed self-report instruments using the Research Electronic Data Capture (REDCap), and participated in a semi-structured clinical interview. Women were given a $\$ 75$ stipend and all study measures and procedures were approved by the Institutional Review Board of the University of Miami.

\section{Measures}

\section{Sociodemographics}

Women were asked to provide demographics including age, ethnicity, education, sexual orientation, and income.

\section{Daily Microaggressions}

Once per day women were sent a link via text message and once they opened the message and clicked on the link it took them to four short questions asking about whether they experienced any microaggressions: (1) In the last $24 \mathrm{~h}$ did someone do or say something subtle that insulted you or showed you less respect than other people? The participants chose either yes or no. If yes, additional questions were triggered. (2) Did the insult have to do with you being __? Check all that apply (Black, a woman, a person living with HIV, gay or bisexual, or other). (3) As a result of these insults today, do you currently feel distressed, and if yes, (4) rate your distress on a scale from 0 to 100 where 100 is the worst you ever felt in your life and 0 is no distress at all. Data on daily microaggressions utilized here was gathered from baseline (October 2019) through July 2020 .

\section{HIV Viral Load (VL)}

Blood specimens were collected at baseline to assay for viral load using the Roche COBAS AmpliPrep/COBAS TaqMan $H I V-1$ Test, v2.0. A viral load cutoff of $<200$ copies $/ \mathrm{ml}$ is utilized in our analyses for viral suppression.

\section{Alcohol and Substance Use}

The Addiction Severity Index (ASI-LITE) [22] captured the frequency with which substances were used over the past 30 days and whether there was problematic use in one's lifetime.

\section{HIV Medication Adherence}

Self-reported adherence to HIV medication for the past week, past 2 weeks, and past 4 weeks was assessed at baseline (/visit 1) and follow up visits 2 and 3 (each followup is approximately 3 months apart). An item developed in previous studies of adherence [23, 24] was used to capture HIV medication adherence. 'Thinking about the past $\mathrm{X}$ weeks, how would you rate your ability to take all your medications as your doctor prescribed them?' Responses were on a 6-point Likert scale ranging from $1=$ 'very poor' to $6=$ 'excellent').

\section{Statistical Analysis}

Using SAS 9.4, Logistic Time-Varying Effect Modeling (TVEM), a nonparametric approach (estimating the changing effect of a variable on an outcome over time) was used to model daily microaggressions and distress. TVEM estimates regression coefficients as continuous functions of time and in doing so, allows the examination of time-varying effects. Herein, the effect of time is allowed to change at each time and because time is treated as continuous, coefficients are not presented in tables but rather in figures that express the coefficient functions, along with pointwise confidence intervals. The coefficient functions are free to vary smoothly with time and are not assumed to follow any parametric form such as linear or quadratic. We used the b-spline method for model estimation, including a random effect for the intercept. Models with 1-5 knots for each daily-varying regression coefficient were run sequentially, with the final model selected based on the minimum AIC and BIC, thus optimizing the balance between model fit and parsimony. First, an intercept-only logistic TVEM was specified to estimate the rate of microaggressions and distress, respectively, as a function of time (days). Second, baseline measures of age, ethnicity, education, income, viral suppression, alcohol use, and substance use were added separately as timeinvariant predictors of microaggressions so that the coefficient function represents in log-odds of microaggressions corresponding to each predictor at a particular day. Education (less than high school, high school graduate, and more than high school) and income $(<\$ 5,000, \$ 5,000-\$ 11,999$, and $>\$ 12,000)$ were aggregated into the smaller categories noted for analyses. Third, negative binomial regression was also used to examine the association between the aggregated count of daily microaggression and daily distress with HIV medication adherence (at visits 2 and 3), respectively, with a generalized estimating equation (GEE) used to address repeated-measures within individuals. Note that viral load data was not available for analyses here as an outcome because COVID-19 resulted in the pausing of in 
Table 1 Sociodemographics and characteristics among 143 BWLWH

\begin{tabular}{l}
\hline \\
\hline Age (mean, sd) \\
Ethnicity \\
Non-hispanic \\
Hispanic \\
Education \\
Eighth grade or lower \\
Some high school \\
High school graduate or GED \\
Some college \\
College graduate \\
Some graduate school \\
Graduate school degree \\
Sex orientation \\
Heterosexual \\
Same gender living (gay or lesbian) \\
Bisexual \\
Asexual
\end{tabular}

Less than $\$ 5,000$

$\$ 5,000$ through $\$ 11,999$

$\$ 12,000$ through $\$ 15,999$

$\$ 16,000$ through $\$ 24,999$

$\$ 25,000$ through $\$ 34,999$

$\$ 35,000$ through $\$ 49,999$

$\$ 50,000$ and greater

Housing

Renting home or apartment

Living in home or apartment owned by you or else

Residential drug, alcohol or other treatment facility

Publicly subsidized housing

A friend or relative's home/apartment

Temporary/transitional housing

Homeless: sleeping in a shelter

Other

Employment

Full time work

Part time work

Full time or part time in school

Neither in work nor in school

On disability

Other

I choose not to answer

Relationship Status

Married

Not married, but living with someone as if married

Non-cohabiting relationship (in a relationship but 13 we do not live together)
Table 1 (continued)

\begin{tabular}{ll}
$\mathrm{N}$ & $\% / \mathrm{sd}$ \\
\hline 53.5 & 10.5
\end{tabular}

\begin{tabular}{llr}
\hline & N & $\% / s d$ \\
\hline Single & 64 & 45.7 \\
Divorced or separated & 11 & 7.9 \\
Loss of long-term partner/widowed & 13 & 9.3 \\
Viral suppressed & 124 & 86.7 \\
Problematic lifetime alcohol use & 51 & 35.7 \\
Any alcohol use (Past 30 days) & 61 & 42.7 \\
Problematic lifetime substance use (exclude & 89 & 62.2 \\
$\quad$ alcohol) & & \\
Any substance use (Past 30 days, exclude alco- & 62 & 43.4
\end{tabular}
hol)

Baseline-90 days follow-up (mean, sd)

$(\mathrm{N}=143)$

Microaggressions

$5.3 \quad 9.3$

Black

Woman

Living with HIV

Gay/bisexual

Other

Distress

$1.6 \quad 3.4$

$2.1 \quad 4.2$

$2.1 \quad 7.2$

$0.2 \quad 0.9$

$1.1 \quad 2.6$

$3.4 \quad 8.1$

HIV medication adherence

Past week

$4.82 \quad 1.32$

Past 2 weeks $\quad 4.78 \quad 1.32$

Past 4 weeks $\quad 4.90 \quad 1.25$

Follow-up (91-180 days) (mean, sd) $\quad(\mathrm{N}=124)$

Microaggressions

Black

$4.1 \quad 11.1$

$1.3 \quad 4.8$

$2.2 \quad 8.3$

$1.6 \quad 8.1$

$0.1 \quad 0.3$

$0.4 \quad 1.1$

$2.4 \quad 8.3$

Distress

HIV medication adherence

Past week

$4.92 \quad 1.36$

$4.89 \quad 1.36$

$4.93 \quad 1.30$

$(\mathrm{N}=114)$

$\begin{array}{ll}2.6 & 8.9\end{array}$

$1.2 \quad 7.3$

$1.2 \quad 5.9$

$1.0 \quad 5.7$

$0.0 \quad 0.1$

$0.1 \quad 0.4$

$1.7 \quad 8.0$

$5.42 \quad 0.96$

$5.46 \quad 0.94$

$5.43 \quad 0.92$ 
person research activities (e.g. blood collection) from March through September of 2020.

\section{Results}

\section{Descriptives}

One hundred and fifty one BWLWH were enrolled in MMAGIC and 143 BWLWH responded to the daily microaggression text at baseline (whose data is utilized here). Sample characteristics are presented in Table 1, but in brief, mean age was 53.5 years (range 21-69), 85.4\% were

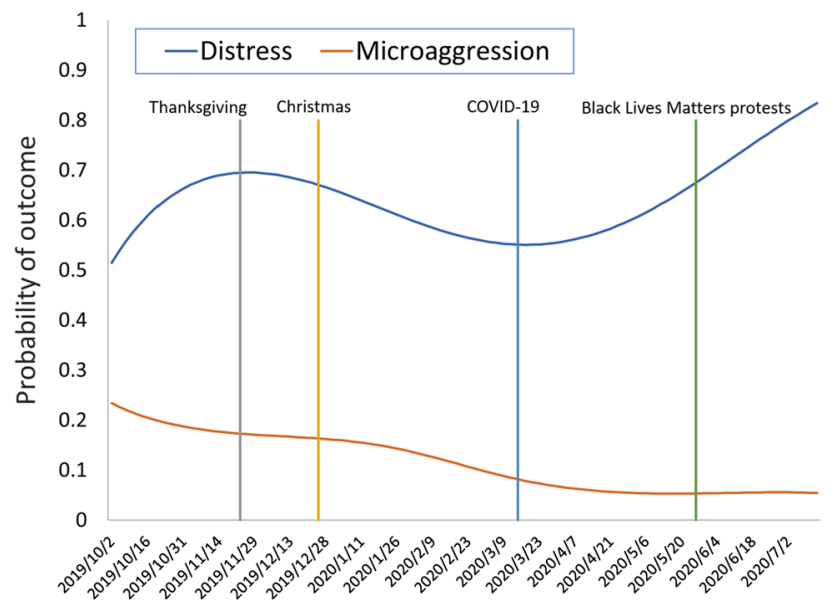

Fig. 1 Estimated probability of daily microaggressions and distress between October 2019 to July 2020 heterosexual, $64.8 \%$ had a high school diploma or above, and $86.7 \%$ were virally suppressed. Self-report medication adherence with a range of 1 (very poor) to 6 (excellent) was rated as 4.90 (baseline), 4.93 (visit 2), and 5.43 (visit 3) on average within the past 4 weeks. There were 17,097 valid daily microaggression logs from October 2nd, 2019 to July 14th, 2020. During the first 90 days follow-up, on average, there were $5.3(\mathrm{sd}=9.3)$ daily microaggressions reported and $74 \%$ of women reported microaggression-related distress during the first 90 days follow-up (see Table 1). From 91 to 180 days, the mean of daily microaggression and distress decreased compared to the first 90 days, and continued to decrease during days 181-270.

\section{Microaggression as a Function of Time}

The probability of daily microaggression and distress as a function of time (day) is shown in Fig. 1. The probability of daily microaggression was around $23 \%$ at baseline in October 2019 , and decreased steadily to over $15 \%$ and remained flat around the holiday season (late November to December, 2019), then continued to decline to below $10 \%$ and remained flat with COVID-19 onset (after late March 2020). The probability of distress shows a different pattern where it increased from $52 \%$ and peaked at $70 \%$ during the holiday season (November to December 2019), then decreased steadily and bottomed around 55\% at the start of the COVID-19 pandemic (March 2019), then began to increase rapidly to $83 \%$ through July 2020.
Table 2 Microaggressions, Distress, Viral Suppression, Substance Use, and Adherence

\begin{tabular}{|c|c|c|c|c|}
\hline & \multicolumn{2}{|l|}{ Microaggression } & \multicolumn{2}{|l|}{ Related distress } \\
\hline & OR $(95 \% \mathrm{CI})$ & $\mathrm{p}$ value & OR $(95 \% \mathrm{CI})$ & $\mathrm{p}$ value \\
\hline Age (1 year increase) & $1.01(0.98,1.04)$ & 0.6398 & $1.02(0.99,1.05)$ & 0.3109 \\
\hline Ethnicity (ref $=$ hispanic) & $0.36(0.05,2.4)$ & 0.2885 & $0.92(0.23,3.61)$ & 0.9008 \\
\hline Education (ref = eighth grade or lower) & $1.22(0.92,1.61)$ & 0.1679 & $1.03(0.78,1.37)$ & 0.836 \\
\hline Sex orientation $(\mathrm{ref}=$ heterosexual $)$ & $1.32(0.7,2.47)$ & 0.389 & $1.27(1,1.63)$ & 0.0516 \\
\hline Income (ref $=$ less than $\$ 5,000)$ & $0.75(0.56,0.99)$ & $0.045^{*}$ & $0.91(0.7,1.17)$ & 0.4549 \\
\hline Viral suppressed $(\mathrm{ref}=\mathrm{no})$ & $0.36(0.14,0.9)$ & $0.0282^{*}$ & $1.08(0.35,3.38)$ & 0.8938 \\
\hline Any alcohol use $(\mathrm{ref}=\mathrm{no})$ & $0.63(0.3,1.34)$ & 0.2308 & $1.38(0.6,3.15)$ & 0.4517 \\
\hline Any alcohol use (Past 30 days) $(\mathrm{ref}=$ no) & $1.04(0.51,2.12)$ & 0.9039 & $2.71(1.07,6.83)$ & $0.035^{*}$ \\
\hline Any substance use (exclude alcohol) $(\mathrm{ref}=\mathrm{no})$ & $0.57(0.26,1.22)$ & 0.1457 & $0.63(0.28,1.44)$ & 0.2768 \\
\hline $\begin{array}{l}\text { Any substance use (Past } 30 \text { days, exclude } \\
\text { alcohol) }(\mathrm{ref}=\text { no })\end{array}$ & $1(0.48,2.07)$ & 0.9981 & $1.12(0.51,2.44)$ & 0.7814 \\
\hline \multicolumn{5}{|l|}{ HIV medication adherence $(\mathrm{ref}=$ very poor $)$} \\
\hline Past week & $1.04(0.98,1.11)$ & 0.2258 & $1.01(0.9,1.12)$ & 0.9098 \\
\hline Past 2 weeks & $1.03(0.97,1.1)$ & 0.3019 & $1.04(0.94,1.16)$ & 0.4513 \\
\hline Past 4 weeks & $1.01(0.95,1.09)$ & 0.6784 & $1.01(0.92,1.12)$ & 0.7993 \\
\hline
\end{tabular}

${ }^{\mathrm{a}} \mathrm{ref}=$ reference group for odds ratio calculations

$*<.05$ 


\section{Microaggresion, Viral Suppression, ART Adherence, Income, and Alcohol Use}

Baseline viral suppression was associated with significantly lower odds of microaggressions (64\%) compared to nonsuppression $(\mathrm{OR}=0.36,95 \% \mathrm{CI}=0.14,0.90, \mathrm{p}$ value $=0.028)$ (Table 2). Higher income at baseline was associated with lower odds of microaggressions $(\mathrm{OR}=0.75,95 \% \mathrm{CI}=0.56$, 0.99 , $\mathrm{p}$ value $=0.045$ ) compared to lower income. In addition, alcohol use in the past 30 days (at baseline) was associated with higher odds of microaggression-related distress $(\mathrm{OR}=2.71,95 \% \mathrm{CI}=1.07,6.83, \mathrm{p}$ value $=0.035)$. Microaggresssions and related distressed were not significantly associated with self-reported HIV medication adherence.

\section{Discussion}

Project MMAGIC is the first study to capture daily microaggressions overtime among BWLWH and our preliminary findings on microaggressions between October 2019 and July 2020, indicated that microaggressions related distress may be impacted by social context. While the probability of microaggressions gradually decreased overtime, microaggression related distress had interesting points of decreases and increases. Microaggressions related distress increased around the holidays perhaps due to increased social gatherings/interactions. However, the distress decreased after the holiday season and flattened around mid-March which is consistent with when COVID19 related social distance mandates were put in place and may have lessened the level of interaction BWLWH had with others outside their home. However, microaggression-related distress began to gradually increase April through May, perhaps as the toll of the pandemic (e.g. deaths, job losses) became more apparent in the U.S and with a disproportionate burden on Black communities [25, 26]. Microaggression-related distress peaked again in early June and persisted through July, a period which overlaps with the murder of George Floyd on May 25, 2020, followed by daily Black Lives Matter protests across the U.S. This backdrop may have intensified the distress resulting from microaggressions that BWLWH experienced.

Further our analyses examining how baseline viral suppression, income, and substance use related to microaggressions and related distress over the 9-month period indicated that baseline viral suppression and higher income was associated with less microaggressions, while baseline alcohol use was associated with higher microaggression related distress. We are unable to draw any casual or directional conclusions and we were limited in our analyses of viral suppression overtime (e.g. unable to treat viral suppression as an outcome due to COVID-related in-person research suspension). In addition, microaggressions were not significantly related to self-reported medication adherence at follow up visits, perhaps due to limitations of a self-report measure and limited variation in women's scores (average was close to 5 [very good] at each visit).

Nonetheless, our preliminary significant findings indicate that there are potentially important bi-directional pathways that need to be considered and explored. Specifically, findings suggest that microaggressions and the related distress experienced and reported by BWLWH may vary as a result of income and alcohol use. Microaggressions and related distress as an everyday manifestation of oppression may negatively impact income and alcohol use [12]. Conversely, higher income may allow some women to select contexts/situations where they are less likely to experience microaggressions (e.g. driving alone in ones car vs. taking the bus/train). Similarly, alcohol use may suggest attempts at coping with already existing distress (due to stressors), that is then exacerbated and reported in response to a microaggression. The association between microaggressions and viral suppression is also complex, yet consistent with existing theories [6,27], and suggests that microaggressions may relate to mental health symptoms and/or health behaviors, which ultimately relates to viral load among BWLWH. Alternatively, women with viral suppression may report less microaggressions, if viral suppression is also a proxy for uncaptured variables such as attention bias towards and recall of positives things, coping, or access to resources which may equip women to select contexts where they are less likely to experience microaggressions.

Despite these interesting findings there are a few limitations to note. First, longitudinal data prevents us form drawing causal conclusions. Second, data was collected among BWLWH in the Southeastern United States thereby limiting the generalizibity to other geographic areas or other individuals living with HIV. Third, future work should capture other indicators of poverty beyond socioeconomic status. Fourth, our measures did not capture factors such as information on the clinics they attend for HIV care, types of jobs and housing, access to personal protective equipment (PPE), barriers to social distancing, and transportation barriers/access, which may all have implaciations for their engagement, adherence, and viral suppression in the context of COVID19. Fifth, the absence of viral load data at visits 2 and 3, limits our examiniation of the relationship between viral load and microaggression to only baseline viral load. Lastly, the self-report medication adherence measure may have been impacted by social desirability bias (average close to 5 [very good] with limited variation) and as such did not serve as a good proxy for viral load at visits 2 and 3 in our analyses. 
While our preliminary findings do not allow us to make causal conclusions, they do support the need for research to both assess microaggression among BWLWH overtime and examine its relationship with medication adherence, viral suppression, and other factors. In addition, our findings for both microaggression experience and related distress suggests that it is insufficient for research to capture microaggression experiences without also measuring related distress. Structural interventions (via policies and laws) are needed to reduce the microaggressions that BWLWH experience each day. In addition, research is needed to develop ecological momentary interventions among BWLWH to improve quality of life and health outcomes. For instance, at the individual level an ecological momentary intervention that both monitors microaggressions experienced by BWLWH (via text or a mobile app) and provides coping strategies (informed by BWLWH) may help to reduce the distress experienced from microaggressions and improve mental health and health behaviors (e.g. engagement in care and medication adherence) and ultimately viral suppression.

Acknowledgements We would like to extend extensive gratitude to the women who participated in this study, research staff, and community stakeholders. The research reported in this publication and the principal investigator (Dr. Sannisha Dale) were funded by R56MH121194 and R01MH121194 from the National Institute of Mental Health (NIMH) and the Office Of The Director, National Institutes Of Health (OD). The content of this publication is solely the responsibility of the authors and does not necessarily represent the official views of the National Institutes of Health.

Author Contributions Dr. SKD, study principal investigator, developed the study hypotheses and procedures for data collection, oversaw the study team, drafted the manuscript, and provided guidance for analyses. YP helped to draft the manuscript, organize the data, and conduct the analyses. NG and SS helped with data collection and provided feedback on the manuscript. IAW, a study co-investigator, provided guidance on data analyses and provided feedback on the manuscript. CMN assisted with data organization/management and reviewed the manuscript. JL helped with data management and reviewed the manuscript. AP was instructmental in participant recruitment/retention and reviewed the manuscript. AER provided medical consultation during data collection and reviewed the manuscript. GHI, SAS, and MLA were study co-investigators who reviewed the manuscript. DJF was a project coinvestigator and provided guidance on data analyses and reviewed the manuscript.

Funding This study was funded by the National Institute of Mental Health and the Office Of The Director, National Institutes Of Health..

Data Availability The data is not available at this time.

Code Availability The code is not available at this time.

\section{Declarations}

Conflict of interest Authors declare that they do not have conflicts of interest.
Consent for Publication No data nor image identifying an individual is published here.

Ethical Approval All procedures performed in this study involving human participants were in accordance with the ethical standards of the institutional and/or national research committee and with the 1964 Helsinki declaration and its later amendments or comparable ethical standards. Procedures were approved by the University of Miami Institutional Review Board.

Informed Consent Informed consent was obtained from all individual participants included in the study.

\section{References}

1. Dale SK, Pierre-Louis C, Bogart LM, O'Cleirigh C, Safren SA. Still I rise: the need for self-validation and self-care in the midst of adversities faced by Black women with HIV. Cult Divers Ethnic Minor Psychol. 2018;24:15-25.

2. Nadal KL, Rivera DP, Corpus JH, Sue DW. Sexual orientation and transgender microaggressions. Microaggr Marginal: Manifest, Dyn, Impact. 2010;26:217-40.

3. Dale SK, Safren SA. Gendered racial microaggressions predict posttraumatic stress disorder symptoms and cognitions among Black women living with HIV. Psychol Trauma Theory Res Pract Policy. 2019;11:685-94.

4. Dale SK, Dean T, Sharma R, Reid R, Saunders S, Safren SA. Microaggressions and discrimination relate to barriers to care among black women living with HIV. AIDS Patient Care STDs. 2019;1;33(4):175-83.

5. Sue DW, Capodilupo CM, Holder A. Racial microaggressions in the life experience of Black Americans. Prof Psychol: Res Pract. 2008;39(3):329.

6. Torino GC, Rivera DP, Capodilupo CM, Nadal KL, Derald WS, editors. Microaggression theory: influence and implications. Hoboken: Wiley; 2018.

7. Hughey MW, Rees J, Goss DR, Rosino ML, Lesser E. Making everyday microaggressions: an exploratory experimental vignette study on the presence and power of racial microaggressions. Sociol Inq. 2017;87:303-36.

8. Swim JK, Hyers LL, Cohen LL, Fitzgerald DC, Bylsma WH. African American College Students' experiences with everyday racism: characteristics of and responses to these incidents. In Journal of Black psychology. New York:SAGE Publications Inc; 2003; Vol. 29, pp. 38-67.

9. Versluis A, Verkuil B, Spinhoven P, van der Ploeg MM, Brosschot JF. Changing mental health and positive psychological well-being using ecological momentary interventions: a systematic review and meta-analysis. J Med Internet Res. 2016;18:e152.

10. Heron KE, Smyth JM. Ecological momentary interventions: incorporating mobile technology into psychosocial and health behaviour treatments. Br J Health Psychol. 2010;15:1-39.

11. Farmer S, Mindry D, Comulada WS, Swendeman D. Mobile phone ecological momentary assessment of daily stressors among people living with HIV: elucidating factors underlying healthrelated challenges in daily routines. J Assoc Nurses AIDS Care JANAC. 2017;28:737-51.

12. Lewis JA, Neville HA. Construction and initial validation of the gendered racial microaggressions scale for Black women. J Couns Psychol. 2015;62:289-302.

13. Logie C, Ll James, Tharao W, Loutfy M. Associations between HIV-related stigma, racial discrimination, gender discrimination, 
and depression among HIV-positive African, Caribbean, and Black Women in Ontario, Canada. AIDS Patient Care STDs. 2013;27:114-22.

14. Microaggression and Bias in the HIV Community-and What We Can Do About It [Internet]. TheBody.com. [cited 2019 Jan 2]. Available from: http://www.thebody.com/content/78275/micro aggression-and-bias-in-the-hiv-community--and.html

15. Eaton LA, Allen A, Maksut JL, Earnshaw V, Watson RJ, Kalichman SC. HIV microaggressions: a novel measure of stigmarelated experiences among people living with HIV. J Behav Med. 2020;43:34-43.

16. Balsam KF, Molina Y, Beadnell B, Simoni J, Walters K. Measuring multiple minority stress: the LGBT people of color microaggressions scale. Cult Divers Ethnic Minor Psychol. 2011;17:163-74.

17. Holland E, Koval P, Stratemeyer M, Thomson F, Haslam N. Sexual objectification in women's daily lives: a smartphone ecological momentary assessment study. Br J Soc Psychol. 2017;56:314-33.

18. Wagner GJ, Bogart LM, Galvan FH, Banks D, Klein DJ. Discrimination as a key mediator of the relationship between posttraumatic stress and HIV treatment adherence among African American men. J Behav Med. 2012;35:8-18.

19. Bogart LM, Landrine H, Galvan FH, Wagner GJ, Klein DJ. Perceived discrimination and physical health among HIV-positive black and Latino men who have sex with men. AIDS Behav. 2013; 17:1431-41

20. Dale SK. Among Black Women Living with HIV in the US Gendered-racial Microaggressions Relates to Lower Medication Adherence [Oral presentation]. Presented at the 13th International Conference on HIV Treatment Adherence. Miami; 2018
21. UNAIDS. 90-90-90, An Ambitious Treatment Target to Help End the AIDS Epidemic. 2014 http://www.unaids.org/sites/defau 1t/files/media_asset/90-90-90_en.pdf

22. Cacciola JS, Alterman AI, McLellan AT, Lin Y-T, Lynch KG. Initial evidence for the reliability and validity of a "Lite" version of the addiction severity index. Drug Alcohol Depend. 2007;87:297-302.

23. Lu M, Safren SA, Skolnik PR, Rogers WH, Coady W, Hardy H, et al. Optimal recall period and response task for self-reported HIV medication adherence. AIDS Behav. 2008;12:86-94.

24. Berg KM, Wilson IB, Li X, Arnsten JH. Comparison of antiretroviral adherence questions. AIDS Behav. 2012;16:461-8.

25. Andrasfay T, Goldman N. Reductions in 2020 US life expectancy due to COVID-19 and the disproportionate impact on the Black and Latino populations. Proc Natl Acad Sci. 2021;118:e2014746118.

26. Chen JT, Krieger N. Revealing the unequal burden of COVID-19 by income, race/ethnicity, and household crowding: US County Versus Zip Code Analyses. J Public Health Manag Pract [Internet]. 2021;27. Available from: https://journals.lww.com/jphmp/ Fulltext/2021/01001/Revealing_the_Unequal_Burden_of_ COVID_19_by.8.aspx

27. Turan B, Hatcher AM, Weiser SD, Johnson MO, Rice WS, Turan JM. Framing mechanisms linking HIV-related stigma, adherence to treatment, and health outcomes. Am J Public Health. 2017;107:863-9.

Publisher's Note Springer Nature remains neutral with regard to jurisdictional claims in published maps and institutional affiliations. 